\section{Ban on South Africans}

SIR-Your first leading article on the question of the South African ban (Nature 318, 195; 1985) castigates the executive committee of the World Archaeological Congress for bowing precipitately to pressure from non-academic bodies. Your second $(319,85 ; 1986)$ fails to mention that a meeting of the full national committee, which includes most of the scholars organizing the individual academic sessions of the congress, convened on 20 November, supported the ban by a considerable majority and reiterated that this was done on grounds of principle rather than pragmatism.

It is, however, clear from the tone and content of both articles that the committee's affirmation of the ban would have had little effect on your general arguments, which could be summarized as stating that while there may be - grudgingly - a case to be made for economic or sports sanctions, there is no case for academic sanctions. The notion that "academic freedom" is an unproblematic concept, that academics have different and more elevated concerns than other people, that academic debates can be, indeed should be, divorced from historical, human and political reality requires vigorous refutation.

This archaeological congress has from the outset laid particular emphasis on being a world congress. Contributions from countries outside the industrialized West were particularly solicited, funds were found to make it possible for people to come to England, and themes were selected that did not simply reflect the preoccupations of "the North". The South African ban must be seen as part of this vision of what an international congress should be, and it must be recognized that failure to implement the ban would lead to the withdrawal of many participants, both from other parts of Africa and from countries expressing solidarity.

Participants at the world congress register as individuals, but their national affiliation is published. The question of admission of South Africa to an international forum cannot therefore be avoided. It might be argued that exclusion isolates and devalues the work of individual academics who have fought against apartheid from within the system. But the ban is not about individuals, it is not, indeed, about academics, it is about bringing pressure to bear on the South African government by boycotting interchanges of any sort, and this policy has the complete support of those organizations within South Africa that speak for the majority of that country's people.

It might be argued that banning South Africa is hypocritical - if South Africa, why not all the other countries that prac- tise violent repression or genocide of "undesirable" ethnic groups? There are two reasons. First, that, unlike the other regimes, in South Africa ethnic stratifi cation is institutionalized as the basis for formal exclusion of the majority from political rights. Second, perhaps more important, there are "historical moments" when particularly repressive action by a regime and reaction by the oppressed reach a point where positive "indignation" expressed in every form available to the outside world may have some effect. The state of emergency declared by the South African regime is one such moment.

One of the aims of academic research in the social sciences is to expose the realities of human social life, and to analyse the bases and causalities of what we observe, but if we restrict our discussion to aca demic forums, if we deem ourselves above politics, we draw the teeth of "academic freedom" and make it into something esoteric and safe. Academics cannot insulate themselves from politics. We have been asked by those within South Africa who risk their lives in opposing the regime to help them by imposing a ban. If we do so, we may also bring pressure to bear on Western governments by convincing them of the strength of their own public opinion. If, in the name of academic freedom we do nothing, we are, whether we like it or not, making a political statement - a negative one.

Your editorial called for plain speaking, and persuasion in the interests of tolerance. We all agree on the need for plain speaking. What some of us are left wondering is what it is you are asking us to tolerate.

B. BENDER

J. GLEDHILL

M. LARSEN

M. ROWLANDS

C. Tilley

Department of Anthropology,

University College London,

Gower Street, London WC1E 6BT, UK

\section{Star colours}

SIR-A recent paper ${ }^{1}$ suggests that some Babylonian, Graeco-Roman and earlymedieval authors considered Sirius to be red in colour. Today it shines white. I wish to argue here that, according to ancient Chinese evidence, (i) Sirius had been white all along but (ii) Betelgeuse has changed colour from yellow to red.

Volume 27, Chronicles of Celestial Officials, in Historical Records edited by Sima Qian of the Han dynasty, in the first century $\mathrm{BC}$, contains the following passage: "The white is like Sirius, the red like Antares, the yellow like Betelgeuse, the blue like Bellatrix, and the dim like
Mirach".

To my knowledge the above assessment was not challenged in any of the twentythree dynastic histories compiled since, which all include chapters based on materials supplied by astronomers royal.

It is possible that the purported attribution of a red colour to Sirius in Babylonian cuneiform texts is a case of mistaken identity ${ }^{2}$. Assertions to the same effect in classical works may be secondary citations by non-expert authors.

In contrast to Sirius, Betelgeuse ( $\alpha$ Orionis) does appear to have altered its colour in the light of ancient Chinese sources. It is now red, with $B-V=1.9$, comparable to the index for Antares (1.8) which the Chinese did regard as red. Being massive, however, Betelgeuse could well have cooled from yellow to red within 2,000 years, during the end of its evolution away from the main sequence into a red supergiant. For Sirius to leave the red giant and reach a white dwarf stage in a similar span of time would be an anomaly, if we accept the current models of stellar evolution ${ }^{1}$.

TONG B. TANG

Department of Physics,

Hong Kong Baptist College,

Kowloon Tong, Hong Kong

1. Schlosser, W. \& Bergmann, W. Nature 318, 45-46 (1985).

2. Brecher, K. \& Feirtag, M. (eds.) Astronomy of the Ancients, 91-115 (MIT Press, Cambridge, 1979).

\section{Radiation threshold}

SIR-John Simpson's review of four books on British nuclear testing in Australia (Nature 318, 319; 1985) claims that the "official view" about the relationship between radiation exposure and ill health and premature death is "that threshold values can be established to distinguish between those who are 'safe' and those 'at risk"". This is incorrect. The concept of a threshold was in common use during the 1920 s and 1930s. For at least the past 35 years, however, radiological protection has been based on the assumption that there is no threshold below which it can be assumed that radiation has no harmful effects. When the International Commission on Radiological Protection was reformed after the war, it made recommendations of maximum permissible exposures at a level that involved a risk small compared with other hazards of life. Subsequent developments of radiological protection philosophy and practice have all been based on the linear no-threshold hypothesis, and it seems increasingly likely that, at least for some important types of radiation, this hypothesis results in an overestimation of the risks ${ }^{1}$.

P. A. H. SAunders

Harwell Laboratory,

Oxfordshire OXI1 ORA, UK

1. Report of the National Research Council Committee on the Biological Effects of lonising Radiation (BEIR), National Academy Press, Washington, DC, 1980. 